\title{
An Analysis of the Thermal Interaction between Components in Power Converter Applications
}

DOI:

10.1109/TPEL.2020.2969350

\section{Document Version}

Accepted author manuscript

Link to publication record in Manchester Research Explorer

\section{Citation for published version (APA):}

Shahjalal, M., Ahmed, M. R., Lu, H., Bailey, C., \& Forsyth, A. (2020). An Analysis of the Thermal Interaction between Components in Power Converter Applications. IEEE Transactions on Power Electronics.

https://doi.org/10.1109/TPEL.2020.2969350

\section{Published in:}

IEEE Transactions on Power Electronics

\section{Citing this paper}

Please note that where the full-text provided on Manchester Research Explorer is the Author Accepted Manuscript or Proof version this may differ from the final Published version. If citing, it is advised that you check and use the publisher's definitive version.

\section{General rights}

Copyright and moral rights for the publications made accessible in the Research Explorer are retained by the authors and/or other copyright owners and it is a condition of accessing publications that users recognise and abide by the legal requirements associated with these rights.

\section{Takedown policy}

If you believe that this document breaches copyright please refer to the University of Manchester's Takedown Procedures [http://man.ac.uk/04Y6Bo] or contact uml.scholarlycommunications@manchester.ac.uk providing relevant details, so we can investigate your claim.

\section{OPEN ACCESS}




\title{
An Analysis of the Thermal Interaction between Components in Power Converter Applications
}

\author{
Mohammad Shahjalal, Md Rishad Ahmed, Member, IEEE, Hua Lu, Senior Member, IEEE, Chris Bailey, Senior \\ Member, IEEE, and Andrew Forsyth, Senior Member, IEEE
}

\begin{abstract}
Accurately predicting the temperature of semiconductor devices is very important in the initial design of power electronics converter. RC thermal models derived from well-known methods have some ability to predict the temperature. However, the accuracy is boundary condition specific, hence, these methods cannot be used in the reliability analysis. To make the thermal model more accurate and robust the factors contributing to discrepancies need to be analyzed carefully. These are powermodule-materials' non-linear properties, thermal grease layer and the cooling system (i.e., liquid-cooled cold plate). In this work, estimation of accurate RC parameters from FEA thermal model is demonstrated in COMSOL. The electrical model having temperature dependent power loss model is coupled to refined thermal model and solved in a circuit simulator, PLECS. The proposed method is applied in two applications: assessing thermal interaction between IGBTs and anti-parallel diodes in a halfbridge power module, and assessing thermal interaction among the discrete switches in an interleaved bidirectional DC-DC converter. Results show that the impact of material non-linearity, thermal grease layer and cooling boundary conditions are significant for accurate prediction of IGBT and diode temperatures. The proposed model is consistent to FEA results and differs by 2-6.5\% comparing to the experimental results.
\end{abstract}

Index Terms - Electro-thermal model, IGBT power module, circuit simulator, finite element analysis, DC-DC converter.

\section{INTRODUCTION}

Power electronic converters that contain multichip power modules are widely used in applications such as hybrid electric vehicles, automotive hybrid traction, or wind power energy conversion. In many of these applications converters are required to handle high current and / or voltage and have to deliver power to a variable load efficiently and reliably in harsh environment [1-3]. Significant improvement in semiconductor technology has accelerated the power handling capability of the converters but the design, manufacturing, and applications of these converters have to meet some new challenges such as the stringent reliability requirements for semiconductor devicesIGBT modules, MOSFET, diodes etc. Because of the changes in mission profile, large time-varying losses are produced in power semiconductor devices and that results in high temperature variations and degradation in the devices [4]. The failure modes in IGBT modules include bond-wire lift off and solder fatigue which is mainly determined by the change of the junction temperatures. Thus, a detailed knowledge about the temperature behaviours of power electronic components are of great interest in the emerging field of power electronics applications, i.e., automotive hybrid traction where the amount of power to be managed is in the order of tens of kilowatts and temperatures can exceed $100^{\circ} \mathrm{C}$ [5].

Coupling the thermal model and temperature dependent power loss models creates the basis for electro-thermal analysis of power electronic systems. There are several methods commonly used for thermal analysis. These include numerical approaches such as computational fluid dynamics (CFD), finite element analysis (FEA), analytical analysis, and lumped equivalent thermal resistor-capacitor (RC) network analysis. Numerical methods such as FEA [6, 7] or CFD [8] are timeconsuming and therefore not suitable for the estimation of junction temperature history for long-time load profiles. The analytical approach solves the 1-D, 2-D, and 3-D heat diffusion equations [9-11] and this meshless method is faster but it is only applicable for simplified structures and it has limited accuracy when modelling the heat convection between the heatsink and the coolant. Moreover, conventional RC type thermal network are faster in estimating junction temperature only. Accuracy is limited due to neglecting thermal couplings between the chips or also in critical layers of materials in IGBT.

Well-known method of impedance determination is usually synthesis of transient thermal impedance matrix, which is based on step power applying on chips, and recording temperatures on chips. This can be either conducted by finite element simulations [6,7] or by experiments [12], [13]. So far, the FEA thermal models are solved at fixed baseplate boundary temperatures or simplified convective boundary conditions. The impact of thermal grease layer and cooling system is still not well-studied. The experimental method involves test rig and complex hardware circuitry to perform temperature measurement. The best possible measurements can be performed to capture case temperatures by embedding either thermistors or thermocouple and IR camera [10], [14]. The synthesized RC network model that is based on mathematical fitting of the the measured two end temperature profile only allows designer to estimate chip junction temperature. Therefore, it cannot be used in determining temperatures at critical locations such as chip solder and baseplate solder.

The typical thermal RC lumped network in the form of either Foster [15] or Cauer [16] network are available for single-chip or multi-chip power module. For multi-chip IGBT module, Foster network is easy to construct using state-of-the-art thermal impedance measurement equipment but it is physically insignificant due to incapability of providing the internal node 


\section{IEEE POWER ELECTRONICS REGULAR PAPER/LETTER/CORRESPONDENCE}

temperature in the structure. Cauer network is physically significant when its parameters are derived from the geometry of IGBT-module layers and material properties. Conventional Cauer method assumes one lumps in thick layers which affects the transient performance. However, for multi-chip IGBT module, because of 3D heat spreading accurate mapping of thermal spreading on the thick layers (e.g. ceramic layer and baseplate layer) is extremely challenging [17]. The accuracy of Cauer network parameters for a multi-chip IGBT module is limited due to uncertainties regarding thermal interfacing and heatsinks in different system.

In conventional Foster and Cauer networks the RC parameters are constant, which is not accurate as the behaviors of components are temperature dependent [18-25]. However, boundary-condition dependent variable RC parameters can increase the accuracy of these models [26]. A new approach for estimating the RC parameters of the Cauer network using the junction temperature cooling curve has recently been presented which does not require power loss information [27]. However, the work focuses only for a single IGBT chip and ignores thermal coupling which might affect the complex heat spreading behavior from baseplate to liquid-cooled cold plate in a multi-chip module.

Although, some thermal models [28-31] take into account the thermal interactions between IGBT chips in a power module, they only provide junction temperature profile instead of the temperature profile in the critical layers of IGBT module i.e. chip solder and baseplate solder which are needed for reliability analysis such as solder cracking.

Adaptive thermal models are implemented in real-time system in estimating the junction temperature as part of health monitoring and further used in analyzing the aging process of an IGBT module $[32,33]$. A new look-up table based thermal model considering the changes in case temperatures due to ageing is proposed in [34] instead of using simplified 1-D average case temperature. The model is difficult to tune with changing boundary condition and does not predict temperature at critical locations of the module. In a simplified thermal coupling impedance model Bahman et al. considered thermal coupling between two adjacent chips instead of taking all the chips into consideration [35]. However, the authors did not consider the thermal grease layer in their module structure and the temperature dependency of the materials was neglected.

In the literature no lumped RC model of multi-chip IGBT module is found which takes into account both material nonlinearity and variable boundary-conditions at the cold plate. An important contribution of the paper is that the presented thermal model is extended to the cooling system as the IGBT module is usually mounted on a liquid-cooled cold plate. The impact of not modelling real cooling system might have significant impact on the estimated RC parameters.

The novelty of the paper can be summarized in the following points: (1) demonstration of accurate lumped RC Foster network derived from FEA thermal simulations of IGBT module and considering physical geometry, material's temperature dependency, thermal grease layer and cooling system, (2) development of temperature dependent loss model and its coupling with the new RC network model, (3) introduction of nonlinear cooling boundary condition into the thermal model and (4) accurate prediction of temperatures at predefined nodes in a specific layer of the module. In this paper, a component thermal interaction model for a half-bridge IGBT module considering all IGBTs and diodes is developed by extracting the thermal model parameters from FEA simulations. Integration of the electrical model and the thermal model is done using PLECS circuit simulator and the effect of thermal coupling is analyzed. The accuracy of the modelling method is also validated against experimental results from a $12 \mathrm{~V}$ to $48 \mathrm{~V}$, $1.5 \mathrm{~kW}$ DC-DC converter.

In the following, Section II describes the modelling framework, the component thermal interaction, parameter synthesis from the FEA simulations. Section III investigates the efficacy of the model for two converter applications. Finally, Section IV draws some conclusions.

\section{METHODOLOGY}

\section{A. Modelling framework}

The electro-thermal analysis modelling framework is shown in Fig. 1. It consists of a circuit simulator (PLECS) and an FEA software package (COMSOL). PLECS is used to model the electrical behavior of the power converter i.e. predicting the power losses of the converter as well as solving the derived thermal RC network. The modelling can be initiated by using PLECS or analytical models to calculate the power losses. The power losses are then used as heat source inputs in COMSOL for FEA thermal analysis of the components in the power electronics system under study. Based on the detailed transient temperature distribution and history in COMSOL an enhanced $\mathrm{RC}$ network model is proposed for semiconductor devices.

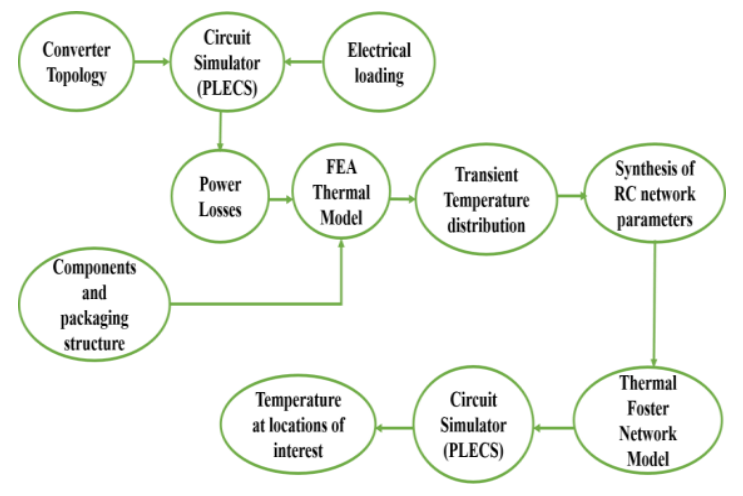

Fig. 1. Electro-thermal modelling method

\section{$B$. The power modules in an inverter}

The thermal behaviors of a half-bridge module have been analyzed using the modelling framework described above. Each module consists of two IGBTs and two antiparallel diodes (Fig. 2 (a)). The IGBT module is assumed to be $1200 \mathrm{~V} / 75 \mathrm{~A}$ Semikron's SKM75GB123D [31]. The IGBT and diode chips are bonded on an aluminum oxide substrate based DBC (Directbond-copper) which is soldered on a copper baseplate. To improve physical integrity and heat transfer, thermal interface material (e.g. thermal grease) is applied between the baseplate 


\section{IEEE POWER ELECTRONICS REGULAR PAPER/LETTER/CORRESPONDENCE}

and the liquid-cooled heatsink. The half-bridge circuit schematic and the cross-section of the IGBT power module are shown in Fig. 2. The material properties obtained from [31] are used in this study.

\section{Modelling of thermal interaction: $R C$ parameter extraction}

The thermal interaction between components can be analyzed using an RC network method. In order to extract the $\mathrm{RC}$ parameters for the RC Foster cells network, the thermal impedance between two thermal nodes along the thermal path of interest is needed. The extraction process of RC thermal parameters using FEA transient thermal responses has been demonstrated in [35] and [30]. The process uses the transformed thermal impedance responses. In this work, FEA has been conducted four times to obtain the thermal responses due to self-heating and cross-heating in the two IGBT-diode pairs. IGBT1, diode1, IGBT2 and diode2 are labelled here as $I_{1}, D_{1}, I_{2}$, and $D_{2}$.

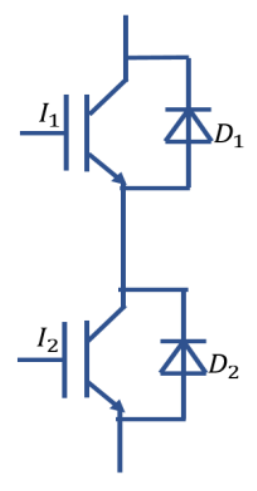

(a)

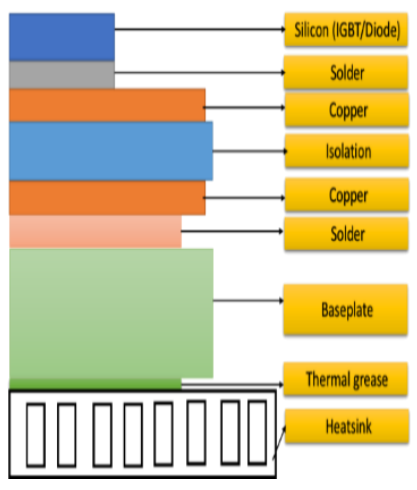

(b)
Fig. 2. (a) Schematic of a half-bridge IGBT power module and (b) simplified cross-sectional view of an IGBT switch

In the first simulation, only $I_{1}$ is considered to be active i.e. no loss in the other three devices and in the second only $D_{1}$ is considered to be active. Similarly, in the third and fourth simulations, only $I_{2}$ and only $D_{2}$ is considered to be active, respectively. The self-heating and cross-heating thermal impedance at selected thermal network nodes are derived from these FEA simulation results. The selected nodes correspond to the locations at the centers of the selected material interfaces as well as the top and bottom of the whole structure. The nodes that correspond to the top of the chip, the interface of chip and chip solder, the interface of substrate solder and baseplate, the bottom of the baseplate are denoted by letters ' $m$ ', ' $n$ ', ' $o$ ', ' $p$ ' respectively (Fig. 3). For the impedances (Z), upper subscript ' $I$ ' and ' $D$ ' symbolize IGBT and diode, respectively. In the following, the lower subscript ' $j$ ', ' $c s$ ', ' $b s$ ', ' $b$ ' respectively denotes the junction, chip solder, baseplate solder, and the baseplate layers, respectively. The temperatures at these selected locations for $I_{1}, D_{1}, I_{2}$, and $D_{2}$ in simulation 1 are $T_{j I_{1}}^{m}, T_{c s I_{1}}^{n}, T_{b s I_{1}}^{o}, T_{b I_{1}}^{p}, T_{j D_{1}}^{m}, T_{j I_{2}}^{m}$, and $T_{j D_{2}}^{m}$, respectively. Only junction temperatures are considered for investigating crossheating from $D_{1}, I_{2}$, and $D_{2}$ in simulation 1 .
D. Thermal impedance network with self-and cross-heating

Considering the linear-time invariant assumption of heat transfer in multichip, the junction temperature in multichip power module can be estimated by forming the thermal impedance matrix shown below:

$\left[\begin{array}{c}T_{j I_{1}} \\ T_{j D_{1}} \\ T_{j I_{2}} \\ T_{j D_{2}}\end{array}\right]=\left[\begin{array}{llll}Z_{\text {th-self }}^{I_{1}} & Z_{\text {th-cross }}^{I_{1}-D_{1}} & Z_{\text {th-cross }}^{I_{1}-I_{2}} & Z_{\text {th-cross }}^{I_{1}-D_{2}} \\ Z_{\text {th-cross }}^{D_{1}-I_{1}} & Z_{\text {th-self }}^{D_{1}} & Z_{\text {th-cross }}^{D_{1}-I_{2}} & Z_{\text {th-cross }}^{D_{1}-D_{2}} \\ Z_{\text {th-cross }}^{I_{2}-I_{1}} & Z_{\text {th-cross }}^{I_{2}-D_{1}} & Z_{\text {th-self }}^{I_{2}} & Z_{\text {th-cross }}^{I_{2}-D_{2}} \\ Z_{\text {th-cross }}^{D_{2}-I_{1}} & Z_{\text {th-cross }}^{D_{2}-D_{1}} & Z_{\text {th-cross }}^{D_{2}-I_{2}} & Z_{\text {th-self }}^{D_{2}}\end{array}\right] *$

$\left[\begin{array}{l}P_{I_{1}} \\ P_{D_{1}} \\ P_{I_{2}} \\ P_{D_{2}}\end{array}\right]+\left[\begin{array}{l}T_{r e f} \\ T_{r e f} \\ T_{r e f} \\ T_{r e f}\end{array}\right]$

where, $T_{j I_{1}}, T_{j D_{1}}, T_{j I_{2}}, T_{j D_{2}}$ are the junction temperature in $I_{1}, D_{1}, I_{2}$, and $D_{2}$ respectively, $Z_{\text {th-self }}^{I_{1}}, Z_{\text {th-self }}^{D_{1}}, Z_{\text {th-self }}^{I_{2}}$, and $Z_{\text {th-self }}^{D_{2}}$ are the total self-heating impedance of $I_{1}, D_{1}, I_{2}$, and $D_{2}$ respectively, $Z_{\text {th-cross }}^{I_{1}-D_{1}}, Z_{\text {th-cross }}^{I_{1}-I_{2}}, Z_{\text {th-cross }}^{I_{1}-D_{2}}, Z_{\text {th-cross }}^{D_{1}-I_{1}}$, $Z_{\text {th-cross }}^{D_{1}-I_{2}}, Z_{\text {th-cross }}^{D_{1}-D_{2}}, Z_{\text {th-cross }}^{I_{2}-I_{1}}, Z_{\text {th-cross }}^{I_{2}-D_{1}}, Z_{\text {th-cross }}^{I_{2}-D_{2}}$, $Z_{\text {th-cross }}^{D_{2}-I_{1}}, Z_{\text {th-cross }}^{D_{2}-D_{1}}, Z_{\text {th-cross }}^{D_{2}-I_{2}}$ are the total cross-heating thermal impedance of $I_{1}-D_{1}, I_{1}-I_{2}, I_{1}-D_{2}, D_{1}-I_{1}, D_{1}-$ $I_{2}, D_{1}-D_{2}, I_{2}-I_{1}, I_{2}-D_{1}, I_{2}-D_{2}, D_{2}-I_{1}, D_{2}-D_{1}, D_{2}-$ $I_{2}$ respectively, $P_{I_{1}}, P_{D_{1}}, P_{I_{2}}$, and $P_{D_{2}}$ are the power losses in $I_{1}, D_{1}, I_{2}$, and $D_{2}$ respectively and $T_{r e f}$ is the reference temperature of the liquid-cooled heatsink.

The self-heating impedances of the IGBT1, diode1, IGBT2 and diode 2 can be expressed by (2), (3), (4) and (5) and the cross-coupling impedances can be represented as simplified form of junction to reference equivalent impedance. Details of the impedances are provided in Fig. 3 and Table I.

$Z_{\text {th-self }}^{I_{1}}=Z_{t h(j-c s)}^{I_{1}}+Z_{t h(c s-b s)}^{I_{1}}+Z_{t h(b s-b)}^{I_{1}}+Z_{t h(b-h)}^{I_{1}}$

$Z_{\text {th-self }}^{D_{1}}=Z_{t h(j-c s)}^{D_{1}}+Z_{t h(c s-b s)}^{D_{1}}+Z_{t h(b s-b)}^{D_{1}}+Z_{t h(b-h)}^{D_{1}}$

$Z_{t h-s e l f}^{I_{2}}=Z_{t h(j-c s)}^{I_{2}}+Z_{t h(c s-b s)}^{I_{2}}+Z_{t h(b s-b)}^{I_{2}}+Z_{t h(b-h)}^{I_{2}}$

$Z_{\text {th-self }}^{D_{2}}=Z_{t h(j-c s)}^{D_{2}}+Z_{t h(c s-b s)}^{D_{2}}+Z_{t h(b s-b)}^{D_{2}}+Z_{t h(b-h)}^{D_{2}}$

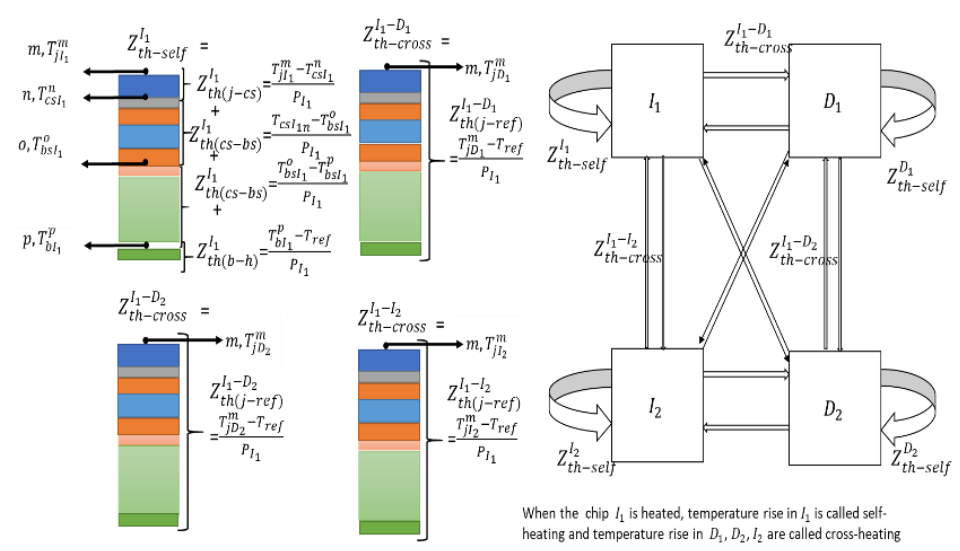

Fig. 3. The total IGBT self-heating and diode cross-heating thermal impedances and the impedances for the material layers 


\section{IEEE POWER ELECTRONICS REGULAR PAPER/LETTER/CORRESPONDENCE}

The extraction process of RC network parameters from the FEA simulated transient thermal impedance responses are described in detail in Section III.

\begin{tabular}{|c|c|}
\hline Symbols & Meaning \\
\hline$Z_{t h(j-c s)}^{I_{1}}, Z_{t h(j-c s)}^{D_{1}}, Z_{t h(j-c s)}^{I_{2}}, Z_{t h(j-c s)}^{D_{2}}$ & $\begin{array}{l}\text { Self-heating impedance of } \\
\text { IGBT1 ,Diode1, IGBT2and } \\
\text { Diode2 between junction } \\
\text { and chip solder }\end{array}$ \\
\hline$Z_{t h(c s-b s)}^{I_{1}}, Z_{t h(c s-b s)}^{D_{1}}, Z_{t h(c s-b s)}^{I_{2}}, Z_{t h(c s-b s)}^{D_{2}}$ & $\begin{array}{l}\text { Self-heating impedance of } \\
\text { IGBT1 ,Diode1, IGBT2 and } \\
\text { Diode2 between chip solder } \\
\text { and baseplate solder }\end{array}$ \\
\hline$Z_{t h(b s-b)}^{I_{1}}, Z_{t h(b s-b)}^{D_{1}}, Z_{t h(b s-b)}^{I_{2}}, Z_{t h(b s-b)}^{D_{2}}$ & $\begin{array}{l}\text { Self-heating impedance of } \\
\text { IGBT1 ,Diode1, IGBT2and } \\
\text { Diode2 between baseplate } \\
\text { solder and baseplate }\end{array}$ \\
\hline$Z_{t h(b-h)}^{I_{1}}, Z_{t h(b-h)}^{D_{1}}, Z_{t h(b-h)}^{I_{2}}, Z_{t h(b-h)}^{D_{2}}$ & $\begin{array}{l}\text { Self-heating impedance of } \\
\text { IGBT and Diode between } \\
\text { baseplate and heatsink }\end{array}$ \\
\hline
\end{tabular}

\section{E. FEA and thermal impedance curves}

Two FEA thermal models are constructed in COMSOL. First one as shown in Fig.4 (a) considers IGBT module without thermal grease and liquid cold plate. While second one as shown in Fig.4 (b) considers IGBT module extended to liquid cold plate through thermal grease layer. The assumptions are made in solving FEA thermal models: (a) all sides are kept adiabatic conditions except top surface of chips and bottom of the either baseplate or cold plate, (b) convective boundary conditions are applied at the bottom of the either baseplate or cold plate, (c) the liquid cooled cold plate material is made up of aluminum and coolant is ethylene-glycol and water mix $(50 \% / 50 \%)$, and (d) the reference coolant temperature is assumed to be constant. In order to derive the thermal impedance values at selected layers, transient FEA simulations were performed four times in which the power loss of either the IGBTs or the diodes were used as the only heat source in the studied structure shown in Fig. 4(a). The material properties used in this FEA model are listed in Table II. The power loss values were considered $110 \mathrm{~W}$ and $60 \mathrm{~W}$ for the IGBT and the diode, respectively, which are adapted from [31]. This power loss values are chosen to benchmark the thermal model by comparing the thermal resistance value to the thermal resistance reported in [31]. The loss was applied at the top surface of the IGBT / diode chips. It is assumed that the module is mounted on a liquid-cooled cold-plate through thermal grease layer and in this simulation a convective heat transfer boundary condition is applied at the bottom of the liquid-cooled cold plate. The total estimated losses were estimated to be $1020 \mathrm{~W}$ for the inverter having six IGBTs and six diodes. The equivalent heat transfer coefficient was estimated approximately as $3000 \mathrm{~W} /\left(\mathrm{m}^{2} \mathrm{~K}\right)$ from (6) for the considered cold plate area $0.017 \mathrm{~m}^{2}$, baseplate temperature $40^{\circ} \mathrm{C}$ and coolant reference temperature, $20^{\circ} \mathrm{C}$. The estimated heat transfer coefficient of the liquid cooling cold plate was applied at the bottom of cold plate in the FEA simulations [36].

$h=\frac{6 * P_{\text {loss }-I G B T}+6 * P_{\text {loss }- \text { diode }}}{\left(T_{\text {baseplate }}-T_{\text {ref }} \text { coolant }\right) * A}$ where, $P_{\text {loss-IGBT }}$ is the power losses in IGBT, $P_{\text {loss-diode }}$ is the power losses in diode, $T_{\text {baseplate }}$ is the baseplate temperature, $T_{\text {ref-coolant }}$ is the coolant reference temperature and $A$ is the heat spreading area of the liquid cooling cold-plate.

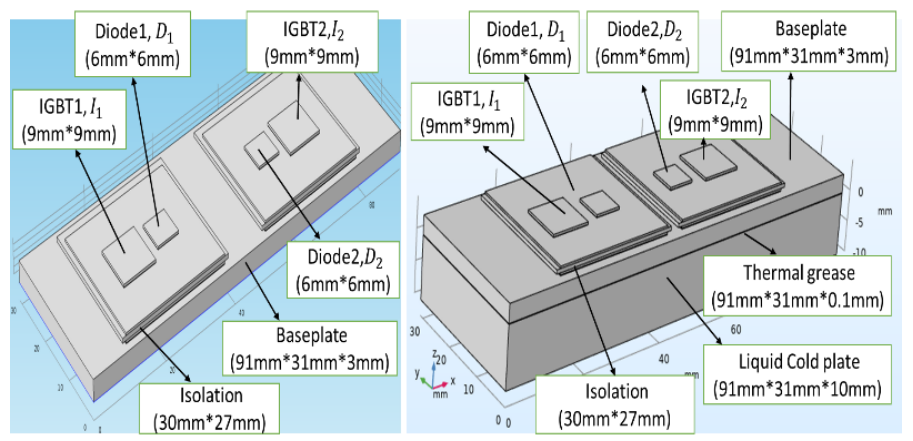

(a)

(b)

Fig. 4. Internal structure of power module in FEA software (a) without liquid cold plate and (b) with liquid cold plate

TABLE II DIMENSION AND MATERIAL PROPERTIES OF THE IGBT MODULE

\begin{tabular}{ccccc}
\hline \hline Material & $\begin{array}{c}\text { Density } \\
\rho, \mathrm{kg} / \mathrm{m}^{3}\end{array}$ & $\begin{array}{c}\text { Temperature } \\
T,{ }^{\circ} \mathrm{C}\end{array}$ & $\begin{array}{c}\text { Specific heat } \\
\text { capacity } \mathrm{c}, \\
\mathrm{J} /(\mathrm{kg} . \mathrm{K})\end{array}$ & $\begin{array}{c}\text { Thermal } \\
\text { Conductivity } \\
\mathrm{k}, W /(\mathrm{m} . \mathrm{K})\end{array}$ \\
\hline IGBT $(\mathrm{Si})$ & 2329 & 25 & 705 & 148 \\
Diode $(\mathrm{Si})$ & & 75 & 757.7 & 119 \\
& & 125 & 788.3 & 98.9 \\
& & 225 & 830.7 & 76.2 \\
& & 325 & 859.9 & 61.9 \\
\hline Solder1 & 9000 & All & 150 & 35 \\
Solder2 & & & & 401 \\
\hline Copper & 8700 & 25 & 385 & 396 \\
layer1 $(\mathrm{Cu})$ & & 75 & 392.6 & 393 \\
Copper & & 125 & 398.6 & 386 \\
layer2 $(\mathrm{Cu})$ & & 225 & 407.7 & 100 \\
Baseplate $(\mathrm{Cu})$ & & 325 & 416.7 & 1 \\
\hline Isolation & 3260 & All & 740 & \\
Thermal & 1180 & All & 1044 & \\
grease & & & &
\end{tabular}

The recorded step transient responses at selected locations from the two FEA simulations for $I_{1}$ and $D_{1}$ are shown in Fig. 6 . The temperature responses are converted to thermal impedance curves using (7) and (8).

$Z_{\text {th }(m-n)}^{\text {self }}=\frac{T_{m}(t)-T_{n}(t)}{P_{\text {self }}}$

$Z_{t h(m-n)}^{\text {cross }}=\frac{T_{m}(t)-T_{n}(t)}{P_{\text {cross }}}$

where, ' $m$ ', and ' $n$ ', correspond to any two consecutive nodes $P_{\text {self }}, P_{\text {cross }}$ describe the power dissipation in the same chip and in the neighbor chip, respectively.

\section{$F$. Thermal parameter extraction}

By fitting the step response equation (9) to the transient thermal impedance curves, $3^{\text {rd }}$ order thermal equivalent Foster RC pair parameters can be obtained. Particle Swam Optimization curve fitting algorithm [37] has been used to fit (9) to the simulated impedance data. 


\section{IEEE POWER ELECTRONICS REGULAR PAPER/LETTER/CORRESPONDENCE}

$Z_{t h}(t)=\sum_{i} R t h_{i} *\left(1-e^{\frac{-t}{R t h_{i}^{*} C t h_{i}}}\right)$

where, $R_{t h i}$ and $C_{t h i}$ respectively corresponds to thermal resistance and thermal capacitance at the $i$ th term.

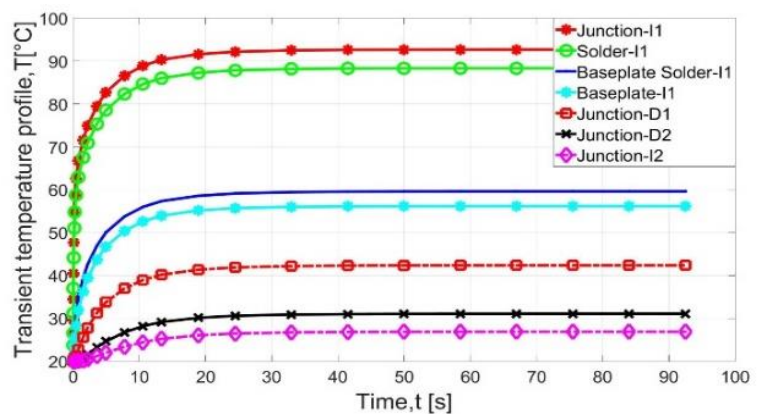

(a)

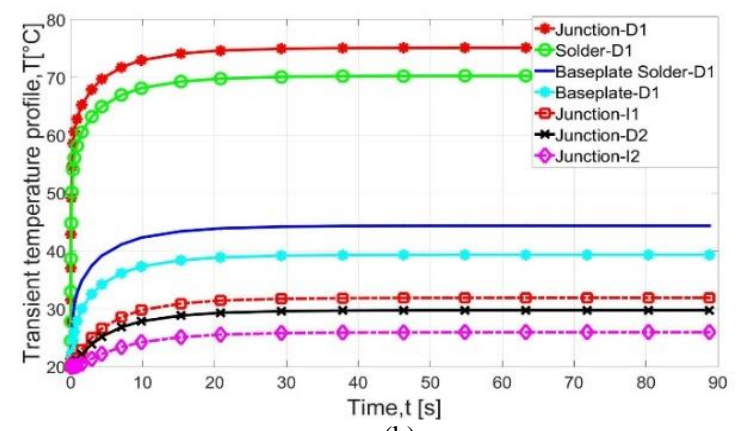

(b)

Fig. 6. (a) Transient temperature profile of IGBT, $I_{1}$ (b) Transient temperature profile of Diode, $D_{1}$

The analysis of thermal coupling has been carried out using a simplified thermal network in which, the cross-heating network is modelled using the two nodes at the junction and at the heatsink and the $3^{\text {rd }}$ order RC pair for this network is extracted to represent all the layers between the two nodes.

Typically, power modules are connected to a heatsink through thermal grease. Adding heatsink to the power module introduces non-linearity due to heat convection process occurred in the heatsink. In addition, thermal spreading and temperature dependent material properties also generate error if linear assumption is applied. Before applying Foster thermal model the impact of non-linear factors on linear assumption has been demonstrated in [24]. The use of temperature dependent material properties as shown above in the simulations gives 5$7 \%$ difference in predicting junction temperature compared to the conventional linear thermal model where material properties are considered to be constant. However, if average temperature dependent thermal properties are used in the simulations to linearize the system, the difference in prediction of junction temperatures becomes $2-5 \%$. In this paper, the nonlinearity of cooling system is modelled by considering the IGBT structure with liquid-cooled cold plate and thermal grease and temperature dependent material properties. This is outlined in the following Sub-section G.

\section{G. Modelling the non-linearity of cooling system}

In this section, a new thermal network is introduced to translate the non-linearity of cooling system and RC parameters are expressed as a function of convective heat transfer coefficient. Converters in real applications does not operate in fixed load and thus produces varying power losses due to varying load. As part of thermal management cooling system is tuned accordingly to maintain the cooling capability by adjusting the flow rate, pressure drop in the flow channel at varying load. Therefore, the use of fixed RC parameters obtained for fixed convective thermal boundary condition is no longer appropriate for varying thermal boundary condition. To circumvent these problems, a generic compact $\mathrm{RC}$ thermal model is required that can adapt the changes of the boundary conditions. Although some recent literature discussed the impact of of various cooling boundary conditions on thermal impedance network $[24,25,35]$, they failed to include either the temperature dependent material properties [24, 25] or thermal grease layer [35] in their models. This paper shows that these simplifications affect the temperature prediction accuracy in electro-thermal simulations.

To tackle non-linearity of thermal boundary conditions, two cases are studied. In case 1 , temperature constant material properties are used. In case 2, temperature dependent material properties are used. To model the capability of cold plate for varying loading conditions, heat transfer coefficient is estimated by (6) based on losses occurred in inverter due to each loading conditions. In both cases heat transfer coefficient, $h$ is varied, $h$ ranges from 1000 to $5000 \mathrm{Wm}^{-2} \mathrm{~K}^{-1}$ and five simulations are conducted for each case. Gathering FEA step response in each case and by processing these data is fitted to generate the compact thermal model.

The most influential thermal path for the device under consideration is baseplate-to-ambient due to the proximity of baseplate layer to cooling system. For case 1, transient thermal impedance curves for $I_{1}, D_{1}, D_{2}$ and $I_{2}$ the thermal path starting are extracted according to varying heat transfer coefficient values. Then the first order RC parameters are extracted by fitting the equation (9) to each thermal impedance curve. The choice of first order RC parameter is due to make the thermal network simple. Afterwards the derived RC parameters are further fitted to obtain a mathematical function of $h$. For self-heating of $I_{1}$, curve-fitted expression of thermal resistance and thermal capacitance as a function of $h$ (only for baseplate-to-ambient thermal path) is shown in Fig.7. Similarly, for cross-heating, curve-fitted expressions of thermal resistance and thermal capacitance as a function of $h$ for $D_{1}, D_{2}$ and $I_{2}$ are shown in Fig.8 (only for junction-to-ambient thermal paths). The method for developing the model for case 2 (temperature dependent material properties in FEA) is exactly the same. 


\section{IEEE POWER ELECTRONICS REGULAR PAPER/LETTER/CORRESPONDENCE}
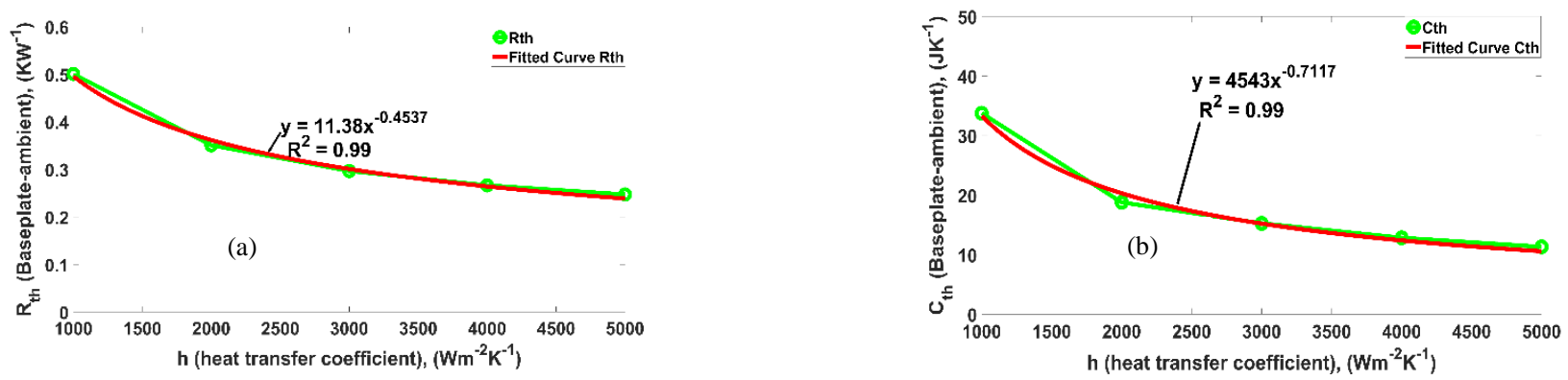

Fig. 7. Curve-fitted thermal resistance and thermal capacitance for varying heat transfer coefficient (a) $I_{1}$, baseplate to ambient thermal resistance (b) $I_{1}$, Baseplate to ambient thermal capacitance
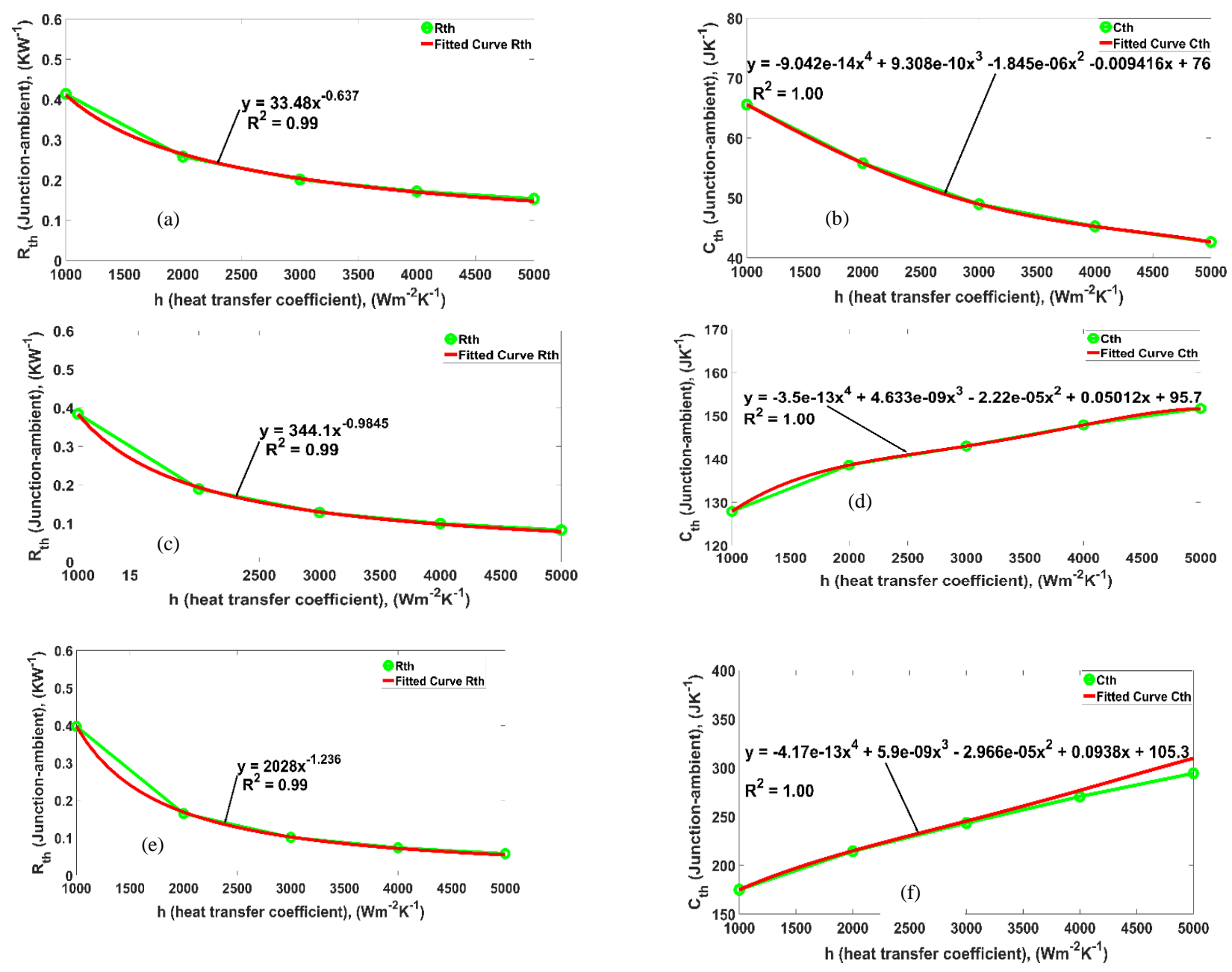

Fig. 8. Curve-fitted thermal resistance and thermal capacitance for varying heat transfer coefficient (a) $D_{1}, R_{t h(j-a)}$ (b) $D_{1}, C_{t h(j-a)}$ (c) $D_{2}, R_{t h(j-a)}$ (d) $D_{2}, C_{t h(j-a)}$ (e) $I_{2}, R_{t h(j-a)}\left(\right.$ f) $I_{2}, C_{t h(j-a)}$

\section{APPLICATIONS}

The method detailed above has been implemented to analyze the thermal behaviors of an IGBT-diode pair in an IGBT module that is used in a conventional three-phase voltage source inverter as shown in Fig. 9. The Figure illustrates the 5
$\mathrm{Hz}$ inverter's electrical circuit that is coupled to the thermal network circuit for the IGBT-diode pair. The power loss is in each IGBT is estimated from the conduction and the switching losses. 


\section{IEEE POWER ELECTRONICS REGULAR PAPER/LETTER/CORRESPONDENCE}

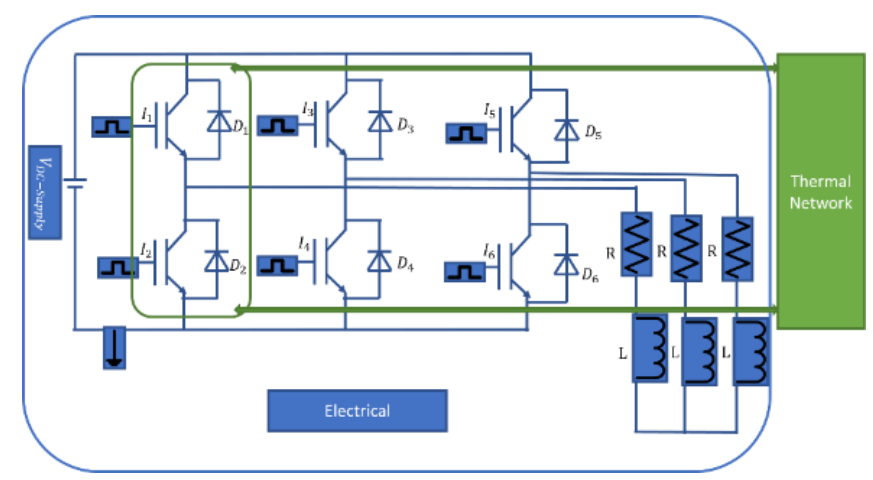

Fig. 9. Coupled Electro-Thermal network circuit for an inverter in PLECS

To facilitate the high accuracy of temperature prediction by electro-thermal model, it is important to construct an accurate loss model. The studied IGBT module is considered in a threephase voltage source converter system. The converter circuit is built in PLECS. One of the salient features of PLECS is its capability of providing an accurate estimation of losses in power converter. This has been demonstrated by few recent works in converter loss modelling [23-25, 38]. Similar approach is applied here to develop lookup table based loss model to estimate power losses based on loading conditions, various operating temperatures and other electrical parameters.

For the thermal analysis, the obtained RC parameters are used in the thermal network circuit model which is shown in Fig.10 for both non-coupled and coupled conditions. For the IGBT (or diode), the thermal circuit consists of four branches of $3^{\text {rd }}$ order RC Foster cells that are connected in series. The thermal branches correspond to the junction to solder, chip solder to baseplate solder, baseplate solder to baseplate and the baseplate to heatsink thermal impedance, respectively. The cross-heating of other chips has been represented by a $3^{\text {rd }}$ order RC Foster cell for the junction to ambient impedance. As shown in Fig. 10 (b), the junction temperature of the IGBT or the diode consists of the contribution from self-heating, cross-heating, and the ambient temperature.

To study the impact of non-linear cooling boundary on thermal model, $\mathrm{RC}$ network parameters are expressed as a curve fitted equation of heat transfer coefficient, $h$. New cooling boundary dependent thermal network is illustrated in Fig. 11. As shown in Fig. 11(a) and Fig. 11(b), the cooling boundary dependent RC parametrized network of the IGBT1 $\left(I_{1}\right)$ and the diode1 $\left(D_{1}\right)$ consists of the contribution from self-heating, cross-heating, and the ambient temperature. The model parameters can be tuned by varying $h$.

Pulsed power loss profiles (frequency $5 \mathrm{~Hz}$ ) for the IGBTs and diodes in the IGBT module in the above mentioned power inverter have been generated using PLECS. Fig.12 describes the power loss profiles for IGBT1 $\left(I_{1}\right)$ and diode1 $\left(D_{1}\right)$, respectively. These profiles are then used in the power module thermal network circuit for the analysis of the thermal coupling effect between the $I_{1}, D_{1}, I_{2}$ and $D_{2}$. The thermal circuit has also been analyzed using PLECS and the total simulation time is $25 \mathrm{~s}$.
Three cases have been analyzed. In case 1, the thermal network RC parameters are derived from FEA simulation using temperature-dependent material properties of silicon and copper. In case 2, the RC parameters are derived from FEA simulation using fixed material properties. In both cases, the cross-heating impedance terms (for $D_{1}, I_{2}$, and $D_{2}$ ) are included in the $\operatorname{IGBT1}\left(I_{1}\right)$ thermal network model. In case 3, the RC parameters do not contain cross-heating thermal impedance terms (conventional approach).

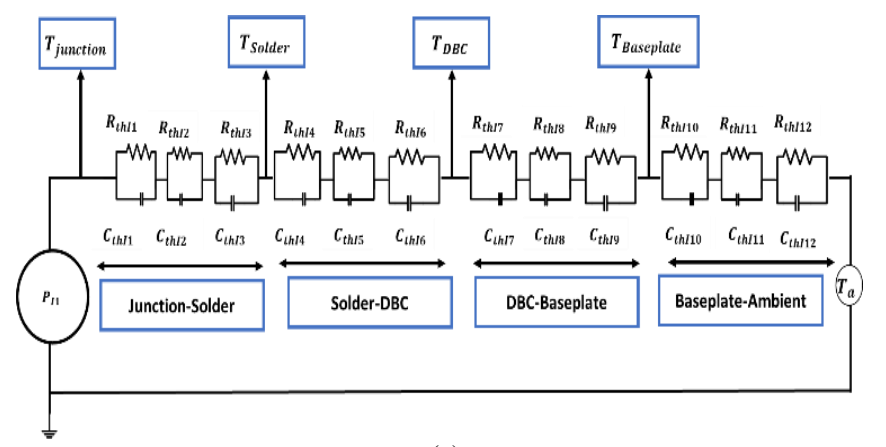

(a)

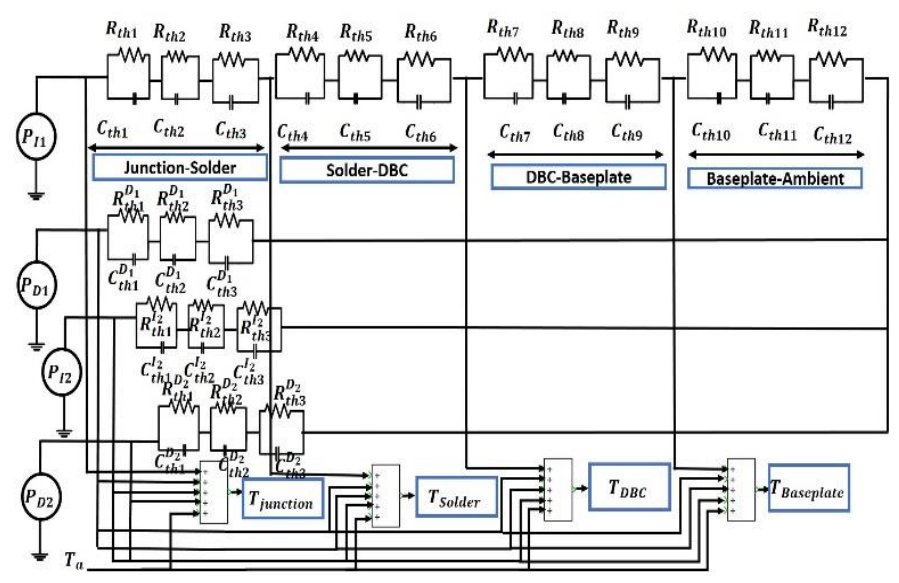

(b)

Fig.10. (a) Non-coupled thermal network of $\operatorname{IGBT1}\left(I_{1}\right)$ (b) Coupled thermal network of $\operatorname{IGBT} 1\left(I_{1}\right)$, diode1 $\left(D_{1}\right), \operatorname{IGBT} 2\left(I_{2}\right)$, and diode2 $\left(D_{2}\right)$.

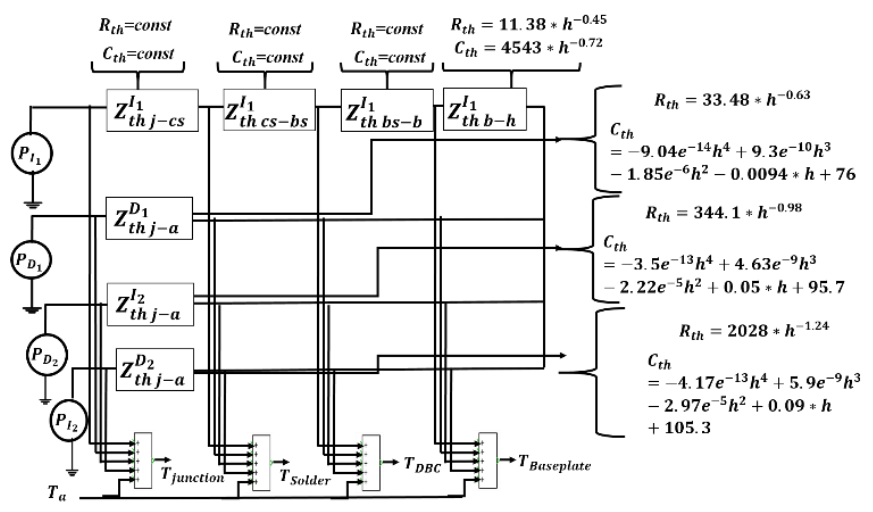

(a) 


\section{IEEE POWER ELECTRONICS REGULAR PAPER/LETTER/CORRESPONDENCE}

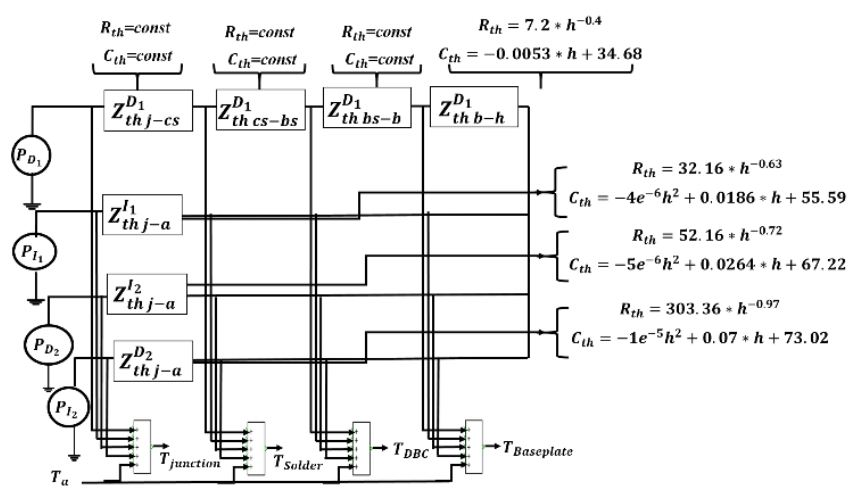

(b)

Fig.11. (a) Cooling boundary dependent coupled thermal network of IGBT1 $\left(I_{1}\right)$ including cross-heating effect of diode $1\left(D_{1}\right)$, diode2 $\left(D_{2}\right)$, and IGBT2 $\left(I_{2}\right)$ (b) cooling boundary dependent coupled thermal network of diode1 $\left(D_{1}\right)$ including cross-heating effect of $\operatorname{IGBT} 1\left(I_{1}\right)$, diode2 $\left(D_{2}\right)$, and $\operatorname{IGBT} 2\left(I_{2}\right)$.

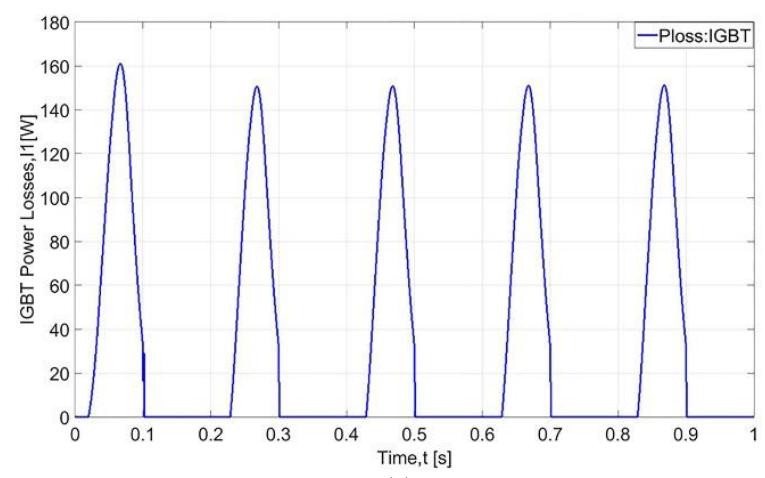

(a)

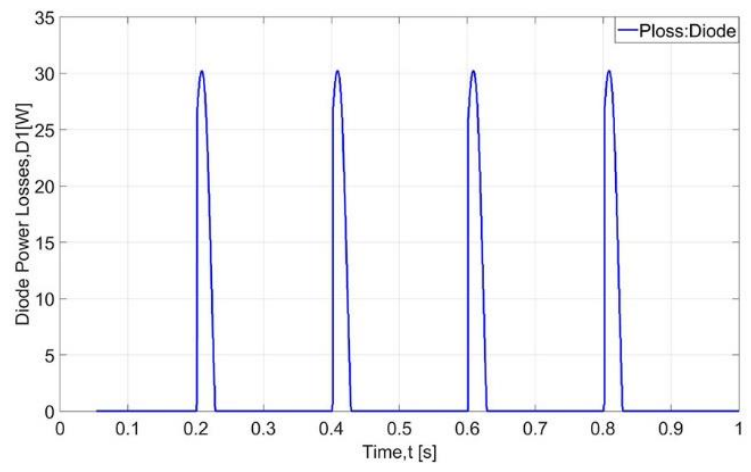

(b)

Fig.12. Average power loss profiles of (a) IGBT1 $\left(I_{1}\right)$ (b) diode1 $\left(D_{1}\right)$

A. Thermal interaction and temperature-dependent material properties effect in the temperature estimation of a half-bridge module

A transient power loss profile is applied to the inverter's thermal model in Fig.9 to investigate the impact of coupling effect and material non-linearity on temperature prediction by the proposed method. Squared power pulses of 160W in IGBT and $30 \mathrm{~W}$ in diode is applied to understand the better thermal dynamics. The applied frequency is $5 \mathrm{~Hz}$. Fig. 13 shows the
IGBT1, $I_{1}$ and diode, $D_{1}$ temperatures for the three cases analyzed in this paper. The time period was considered between 22 and $22.2 \mathrm{~s}$ when steady state has been reached.

As can be seen in Fig. 13(a), the IGBT1 junction temperatures for case 1 (temperature-dependent) and case 2 (temperatureindependent) differ by about $1.95^{\circ} \mathrm{C}$, and case 1 and case 3 (non-coupled) differ by about $9.8^{\circ} \mathrm{C}$. This shows that both the thermal coupling and the temperature dependent material properties affect temperature predictions, but the thermal coupling has a greater effect. Similar discrepancy is also observed at chip solder, baseplate solder, and baseplate temperatures. The predicted temperature difference between case 1 and 3 is about $12.16^{\circ} \mathrm{C}, 12.14^{\circ} \mathrm{C}$, and $11.8^{\circ} \mathrm{C}$ respectively at chip solder, baseplate solder, and baseplate, respectively. Fig. 13(b) shows the junction temperature of the diode. Once again, the effects of material property and thermal coupling are significant. However, for diode, $D_{1}$ the temperature difference between case 1 and 3 is about $24.7^{\circ} \mathrm{C}$, which is much greater than for the IGBT, $I_{1}$. The difference is about $24.8^{\circ} \mathrm{C}, 25.9^{\circ} \mathrm{C}$, and $24.8^{\circ} \mathrm{C}$ respectively at chip solder, baseplate solder, and baseplate respectively. This can be attributed to the fact that high dissipated power loss in $I_{1}$ causes the heat flux to spread and interact with adjacent $D_{1}, D_{2}$, and $I_{2}$ and thereby, influencing the temperature of closely adjacent diode, $D_{1}$.

The temperature predicted by this proposed model were also compared to our previous work that did not include thermal grease layer [39]. Neglecting thermal grease layer in the model causes the temperature difference of $I_{1}$ at junction, solder, baseplate solder, and baseplate by $10.23^{\circ} \mathrm{C}, 11.08^{\circ} \mathrm{C}, 13.64^{\circ} \mathrm{C}$, and $11.14^{\circ} \mathrm{C}$, respectively compared to the case 1 results. For $D_{1}$ temperature differs at junction, solder, baseplate solder, and baseplate by $10.97^{\circ} \mathrm{C}, 11.38^{\circ} \mathrm{C}, 12.05^{\circ} \mathrm{C}$, and $11.92^{\circ} \mathrm{C}$ respectively compared to the case 1 results. It can be seen that the impact of thermal grease layer and material non-linearity is significant for predicting temperatures in the IGBT modules. This is due to the fact that thermal grease layer contributes to increase the thermal resistance and thermal capacitance in the baseplate to ambient layer.

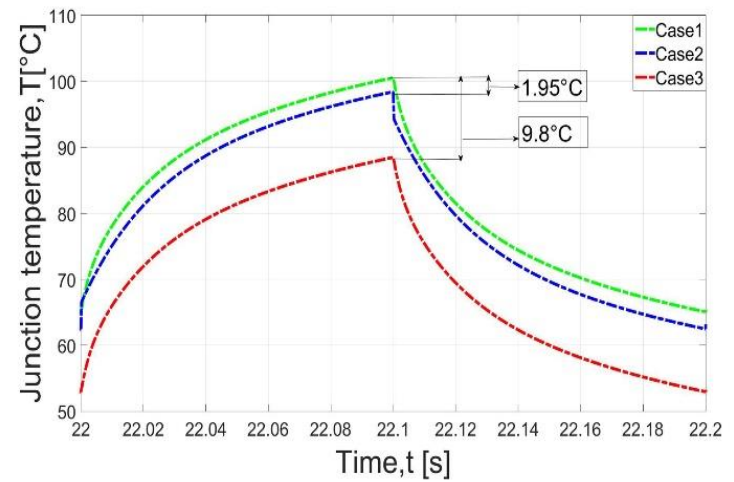

(a) 


\section{IEEE POWER ELECTRONICS REGULAR PAPER/LETTER/CORRESPONDENCE}

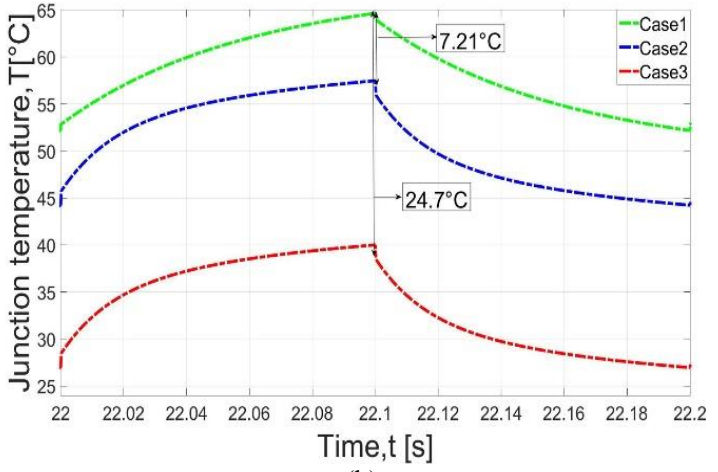

(b)

Fig. 13. Dynamic junction temperature profile of (a) IGBT1 and (b) diode1. Case 1- temperature dependent material properties, Case 2- fixed material properties and Case 3- no thermal coupling

B. Cooling boundary-dependent material nonlinearity effect in the temperature estimation of a half-bridge module

With the new thermal network presented in Fig. 11, the transient load profile is applied to the inverter in Fig. 9. Similar three cases are studied by the proposed RC thermal model considering (1) non-linear material properties, (2) constant material properties and (3) thermal non-coupling. The purpose of this study is to identify the impact of material non-linearity, cooling boundary and the errors of thermal model due to applying the boundary condition at the bottom of baseplate instead of heatsink. The results shown in Fig. 14 has clearly demonstrated that the case 2 still underestimates the junction temperature of IGBT1 and diode 1 by $11.2^{\circ} \mathrm{C}$ and $3.42^{\circ} \mathrm{C}$ respectively comparing to case 1 and the impact of thermally non-coupling is glaringly obvious on the temperature prediction. The discrepancies in case of prediction of junction temperature of IGBT1 and diode1 are about $12.72^{\circ} \mathrm{C}$ and $25.24^{\circ} \mathrm{C}$, respectively between case 1 and case 3 . The estimation errors in junction temperatures are $12.92 \%$ and $45 \%$ for the IGBT1 and the diode1 respectively due to not considering thermal coupling effect. The higher thermal coupling effect is more pronounced in diode 1 due to high power losses in IGBT1 and thus the prediction error is significant.

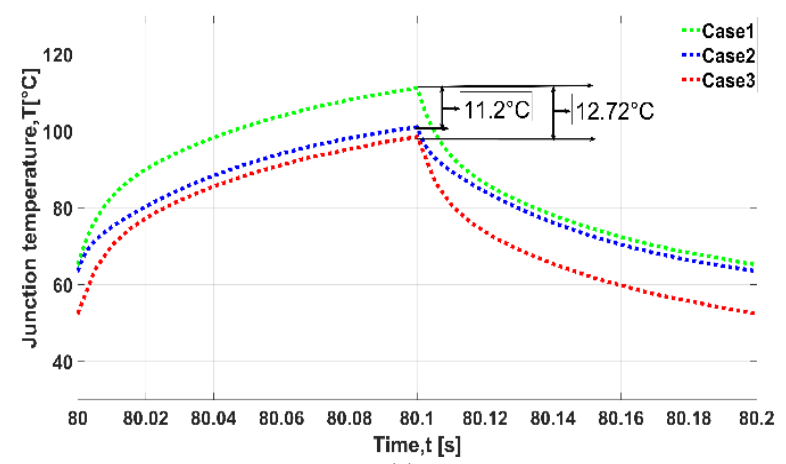

(a)

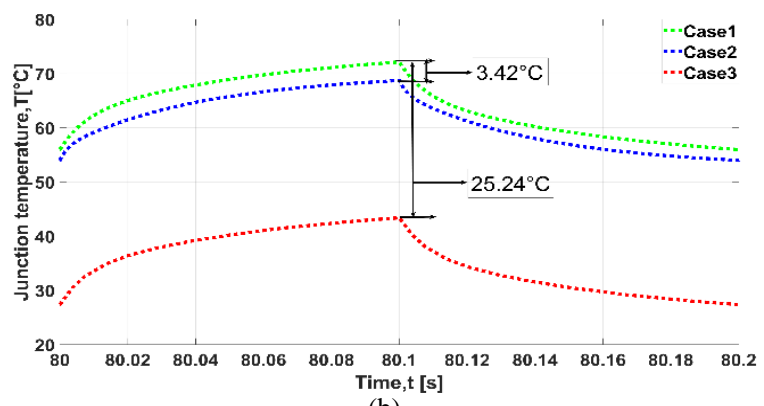

(b)

Fig. 14. Estimated dynamic junction temperature profile of (a) IGBT1 and (b) diode1. Case 1- improved cooling boundary dependent model @ temperature dependent material properties, Case 2-improved cooling boundary dependent model @ temperature independent material properties and Case 3- no thermal coupling

In order to verify the accuracy of the proposed cooling boundary dependent $\mathrm{RC}$ network method, a test case scenario is set up in both FEA and proposed circuit method. In both cases similar dynamic loss profile obtained from the converter loading is applied and $h$ is considered $2500 \mathrm{Wm}^{-2} \mathrm{~K}^{-1}$. The predicted temperature responses from proposed method are compared with the FEA results. As it is shown in Fig. 15, FEA results are consistent with the proposed method and the maximum peak-to-peak temperature error between two methods is $3 \%$ and $4 \%$ for the IGBT1 and the diode1, respectively. It is worth to mention that FEA takes 40 minutes to solve a 100s dynamic loss profile with a desktop computer with core i7 processor system while proposed method only takes 10 s to solve in circuit-simulation platform. In practice, converter design experiences long mission profile (i.e. a yearly mission profile for wind turbine system). FEA will not be suitable tool to handle the long mission profile due to memory and processing speed concerns.

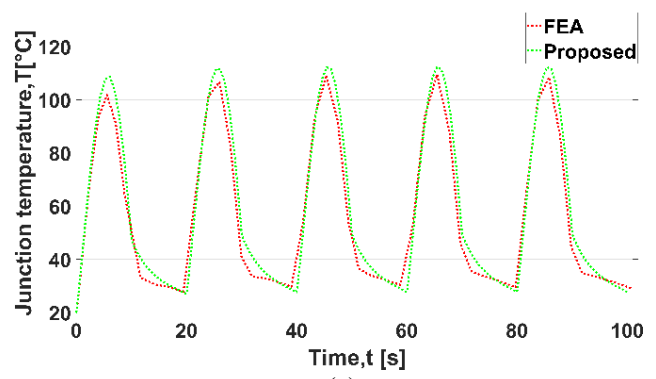

(a)

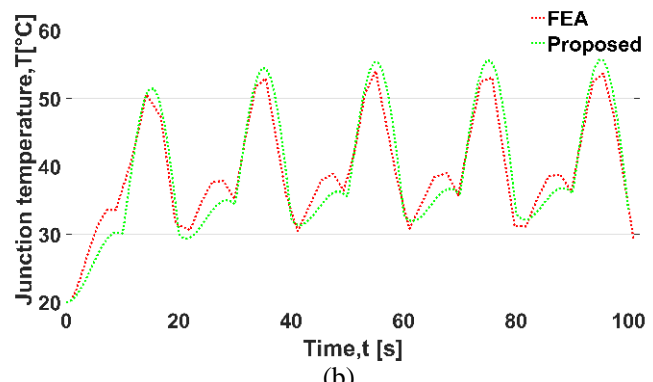

(b)

Fig. 15. Estimated dynamic junction temperature profile of IGBT1 (a) \& (b) and diode 1 by proposed and FEA. 


\section{IEEE POWER ELECTRONICS REGULAR PAPER/LETTER/CORRESPONDENCE}

\section{Comparison between experiments and simulation for a DC-} DC converter

In order to evaluate the accuracy of the proposed modelling method, the experimentally observed temperature profile in a power electronic converter [40] is compared with the results from the electro-thermal analysis of the converter. The thermal interactions caused by the conduction and switching losses in the power semiconductor devices are validated using the proposed modelling approach. A high bandwidth infrared thermal camera (FLUKE TiS 10) is used to observe the temperature distribution between four MOSFETs ( $\mathrm{Si}$ CoolMOS, IRF7759L2TRPBF) during the operation of converter. The circuit topology and experimental setup are illustrated in Fig. 18. The converter is a bidirectional interleaved DC-DC converter $(1.5 \mathrm{~kW}, 12 \mathrm{~V}$ to $48 \mathrm{~V})$ with an interphase transformer (IPT). A DC power supply is used to feed the converter with constant DC voltage as input and a variable resistive load is connected at the output; thereby the current loading of the device can be adjusted. In Fig. 16 (a) all the capacitors are multi-layer ceramic capacitors and the $\mathrm{L}_{\text {in }}$ is an amorphous alloy core based filter inductor. T1-T4 are $\mathrm{Si}$ CoolMOS (MOSFET) from Infineon, IRF7759L2TRPBF in DirectFET L8 package. The switching frequency of the converter was $40 \mathrm{kHz}$. During boost-mode operation of the converter T1 and T3 are turned off using zero gate bias, so the body diodes D1 and D3 are active in the converter. T2 and T4 works as main MOSFET in the boost cells. Only the temperature distribution during boost-mode experiments are shown in this Section.

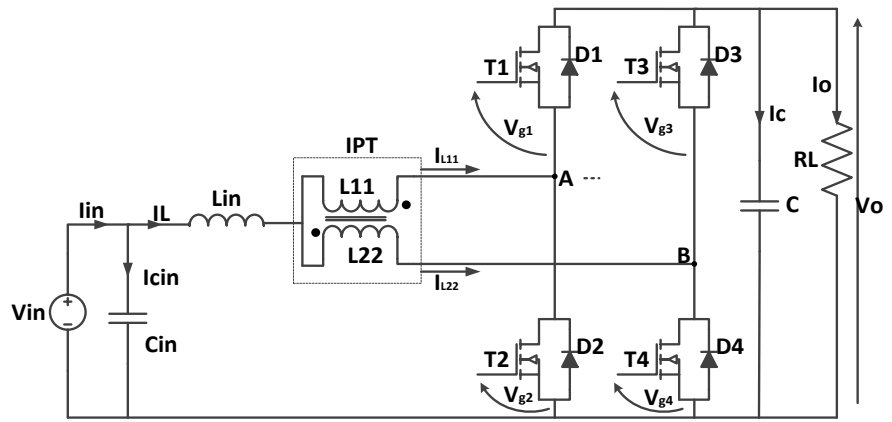

(a)

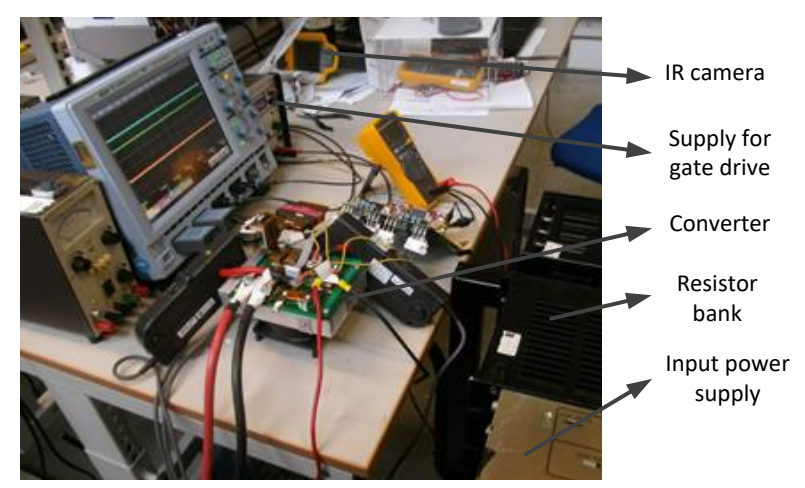

(b)

Fig. 16. Experimental validation of electro-thermal analysis of a DC-DC converter (a) circuit Topology (IPT based dual interleaved bidirectional converter) and (b) Experimental setup
The MOSFETs were soldered on top of an insulated metal substrate board (TCLAD board) with $2 \mathrm{oz}$ copper and $1.02 \mathrm{~mm}$ Al base plate. The TCLAD board was screwed on top of an aircooled Al heatsink. Silicone grease was used as thermal interphase material (TIM) between the TCLAD board and the heatsink. On the top-side of the MOSFETs two L-shaped copper heatsinks were connected. A silicone polymer thermal pad $(1 \mathrm{~mm})$ is used between the Can and the copper heatsink for each MOSFET. Both filter inductor and IPT was placed above the TCLAD board. Therefore, effect of their losses on the TCLAD board and the heatsinks can be considered negligible.

At the rated operating condition of the converter, $1.5 \mathrm{~kW}$ and $12-48 \mathrm{~V}$, power loss (switching plus conduction) in each of T2 and T4 was $13.7 \mathrm{~W}$. Power loss in each of T1 and T3 was 9.8 $\mathrm{W}$ [40]. Ambient temperature was varied in the range of 21$25^{\circ} \mathrm{C}$. Two FEA models are constructed. In the first FEA model, material properties $(\mathrm{Si}, \mathrm{Cu})$ are temperature dependent while in the second FEA model, material properties are constant. The proposed RC lumped thermal network that establishes temperature dependency of the thermal resistance and capacitance is shown in Fig.17. The power losses for T1-T4 are applied in both FEA thermal model of the converter and the temperature problem is solved. The self-heating and crossheating has been considered. Fig. 18 shows the temperature distribution of the MOSFETs, heatsinks, TCLAD and interface materials in the converter. Using the FEA derived transient thermal responses, thermal network parameters have been extracted (similar to the process explained in Section II.E). Then later three thermal models (coupled_ $T_{\text {dependent }}$, coupled_ $T_{\text {constant }}$ and non-coupled) have been analyzed in PLECS by integrating converter electrical model with thermal model. For simplicity, to demonstrate the coupling effect, only $\mathrm{T} 2$ is modelled considering self-heating and cross-heating. The coupled model includes all the MOSFET interactions while the non-coupled considers only the self-heating of $\mathrm{T} 2$. The temperature profiles for $\mathrm{T} 2$ (top of copper heatsink) using coupled_ $T_{\text {dependent }}$, coupled_ $T_{\text {constant }}$ and non-coupled model is plotted in Fig. 19. The steady-state temperature difference is $9.9^{\circ} \mathrm{C}$ between the coupled_ $\mathrm{T}_{\text {dependent }}$ and the non-coupled model. The steady-state temperature difference is $7.9^{\circ} \mathrm{C}$ between the coupled_ $T_{\text {constant }}$ and the non-coupled model. As in the non-coupled model, only a self-heated heat source is considered and the heat flux spreading contributed by the other MOSFETs are ignored, it provides an inaccurate result.

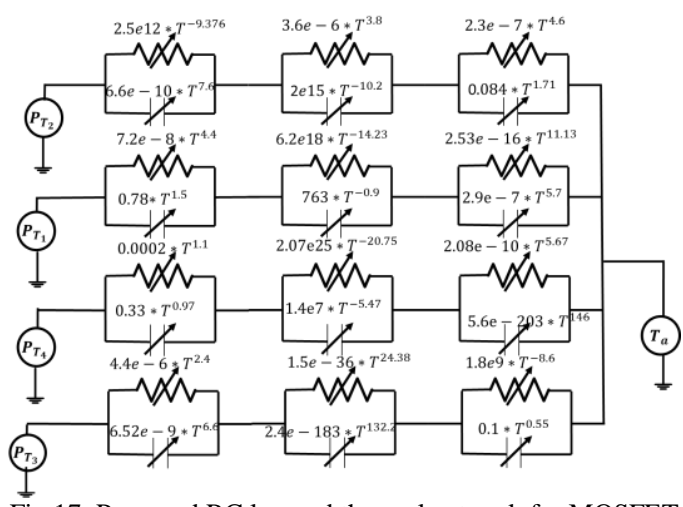

Fig.17. Proposed RC lumped thermal network for MOSFET 


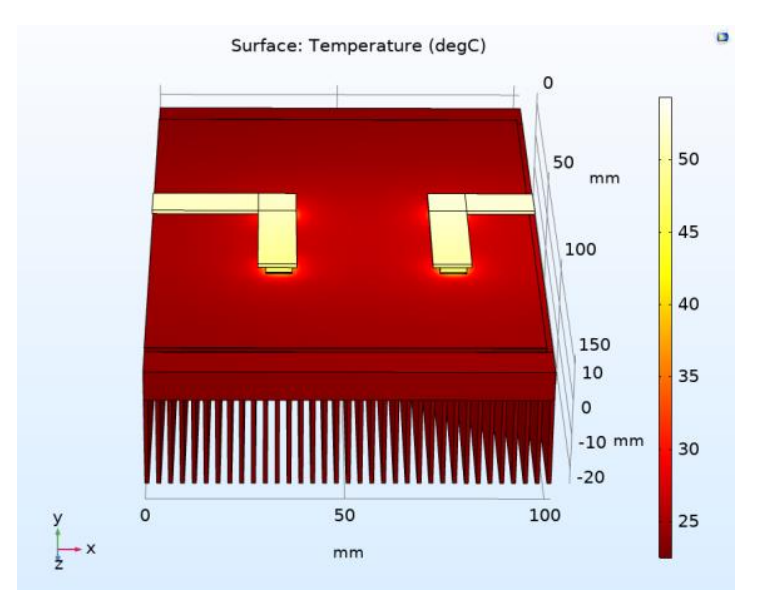

Fig. 18. FEA modelling of IPT based dual interleaved bidirectional DC-DC converter

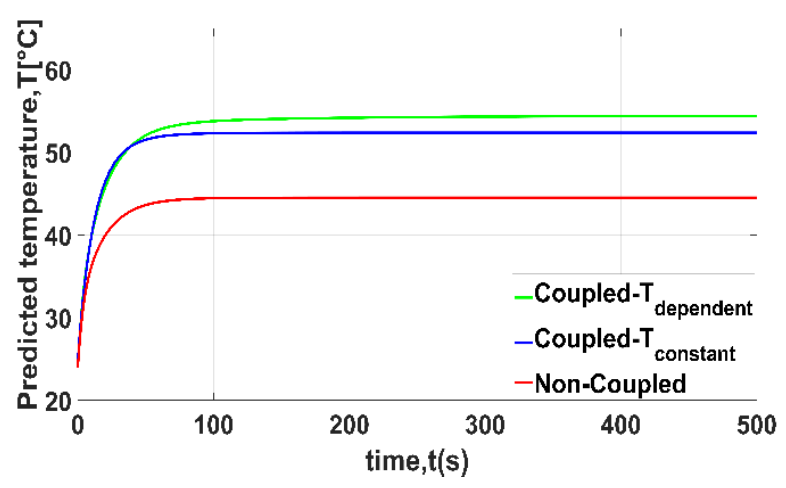

Fig. 19. Predicted temperature on the top surface of the copper heatsink where $\mathrm{T} 2$ is connected - difference between the proposed coupled and conventional non-coupled approaches

A thermal image of the MOSFETs taken by the infrared camera is shown in Fig. 20 at the rated operating condition of the converter $(1.5 \mathrm{~kW}, 12 \mathrm{~V}$ input to $48 \mathrm{~V}$ output). The temperatures on the top surface of the copper heatsink where MOSFETs are connected can be clearly observed. High emissivity white paint was put on the top surface of the heatsink where MOSFETs are connected to allow accurate temperature measurement using the infrared camera. The observed temperatures for $\mathrm{T} 4, \mathrm{~T} 3, \mathrm{~T} 2$ and $\mathrm{T} 1$ are $55.8^{\circ} \mathrm{C}, 55.4^{\circ} \mathrm{C}, 55^{\circ} \mathrm{C}$ and $55.1^{\circ} \mathrm{C}$, respectively. In Fig. 20 (a), at the edge of L-shaped copper heatsink positioned at $\mathrm{T} 3$, temperature is slightly higher, around $68.6^{\circ} \mathrm{C}$. This is due to the improper use of the white paint. The thickness of white paint at that particular edge was higher which may have worsened the surface emissivity in that particular location. Also, reflection from nearby components (copper connectors on the TCLAD) and thermal radiation of the surroundings can affect the measurement.
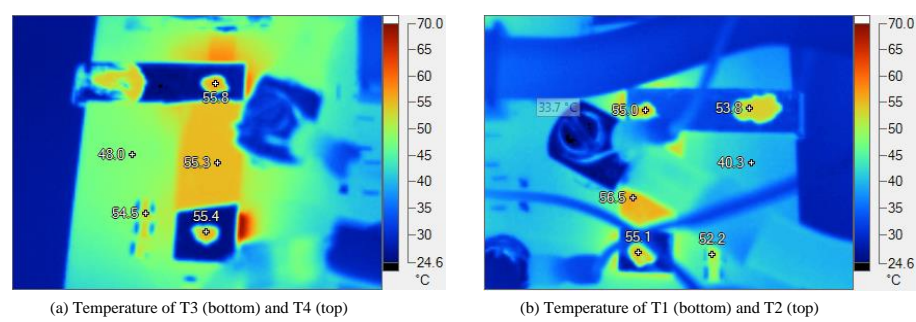

Fig. 20. Temperature of different components (a) temperature of T3 (bottom) and T4 (top) and (b) temperature of T1 (bottom) and T2 (top) when the DCDC converter is running at $1.5 \mathrm{~kW}$

The steady state temperature of the top surface of copper heatsink where $\mathrm{T} 2$ is connected obtained by two methods (proposed modelling and FEA) are listed in Table III along with the experimental result. The observed steady-state temperatures from FEA simulations for $\mathrm{T} 4, \mathrm{~T} 3, \mathrm{~T} 2$ and $\mathrm{T} 1$ are $54.01^{\circ} \mathrm{C}$, $52.18^{\circ} \mathrm{C}, 54.8^{\circ} \mathrm{C}$ and $51.39^{\circ} \mathrm{C}$, respectively. It is worth to note that the temperatures agree well, although a small variations of $1.2{ }^{\circ} \mathrm{C}$ is observed for $\mathrm{T} 2$ switch between the proposed model and the experiment. Predicted T2 temperature from the proposed circuit method differs by $0.7 \%$ and $3 \%$ compared to the FEA simulation and the experiment, respectively. The FEA result agrees well with the experimental results for other switches (i.e. T4, T3, and T1) and it differs by $1.8 \%, 5.1 \%$, $6.5 \%$ compared to the experiment, respectively. This discrepancy might generate due to neglecting the effect of thermal coupling of other components and the simplification of the converter set-up and the simplified MOSFET package used in the FEA simulation. The DirectFET package was simplified in this analysis. Also the current density in the copper tracks of the TCLAD board was very high causing around $18 \mathrm{~W}$ loss in them during experiment at the rated operating condition [37]. This loss was neglected in the FEA simulation which can influence the thermal equivalent Foster network parameters in the proposed model.

TABLE III STEADY STATE TEMPERATURE OF MOSFET, T2 IN AN INTERLEAVED DC-DC CONVERTER

\begin{tabular}{|l|l|l|l|}
\hline $\begin{array}{l}\text { Temperature } \\
\left({ }^{\circ} \mathrm{C}\right)\end{array}$ & Proposed model & FEA & Experimental \\
\cline { 2 - 4 } & $53.4^{\circ} \mathrm{C}$ & $54.8^{\circ} \mathrm{C}$ & $55^{\circ} \mathrm{C}$ \\
\hline
\end{tabular}

\section{CONCLUSIONS}

Accuracy of any thermal model depends on precise modelling of component thermal interaction, module or device geometry, material non-linearity, accurate measurement of critical layers and cooling system (i.e. liquid-cooled cold plate and extruded air-cooled fin heat sink). In this work, a methodology for solving electro-thermal problems of power electronics components (IGBT power module and discrete FET package) is proposed using an enhanced RC network model. The RC thermal network parameters are extracted from FEA simulations considering the impact of nonlinear cooling boundary conditions and self- and cross-coupling thermal impedances.

The analysis presented in the paper has demonstrated that the estimated temperatures of IGBT and diode using the proposed $\mathrm{RC}$ network is more accurate compared to the traditional RC 


\section{IEEE POWER ELECTRONICS REGULAR PAPER/LETTER/CORRESPONDENCE}

network which is derived by applying the convective cooling boundary conditions at the bottom of baseplate instead of at the bottom of liquid-cooled cold plate or heat sink. To further validate the accuracy of the proposed modelling approach, estimated temperatures of the MOSFETs in a dual interleaved DC-DC converter are compared with the experiments and FEA simulation. The predicted temperature of the MOSFETs is very close to the FEA results but differs by $2-6.5 \%$ from the experimental result. This is thought to be caused by the simplification of the MOSFET package in the FEA model due to lack of detailed structural and material information of canto-drain layer of the MOSFET package. The analysis shows that the proposed approach can increase the accuracy of the temperature prediction for a specific component if geometrical and material details of the component are known. Because of the fast and accurate simulation, the proposed method could enable more accurate reliability assessment at the initial design stage of a power electronics converter resulting in a more effective guide to reliable hardware prototyping and further qualification test. Additionally, it can help develop a modelbased observer that can be implemented in real-time health monitoring purpose.

\section{ACKNOWLEDGMENT}

Mohammad Shahjalal was the recipient of a Vice Chancellor Scholarship from the University of Greenwich. Hua $\mathrm{Lu}$ and Chris Bailey would like to acknowledge the financial support of EPSRC through the "Underpinning Power Electronics 2012: Components Theme” project (reference: EP/K034804/1).

\section{REFERENCES}

[1] M. März, A. Schletz, B. Eckardt, S. Egelkraut, and H. Rauh, "Power electronics system integration for electric and hybrid vehicles," in Integrated Power Electronics Systems (CIPS), 2010 6th International Conference on, 2010: IEEE, pp. 1-10.

[2] H. Wang, M. Liserre, and F. Blaabjerg, "Toward Reliable Power Electronics: Challenges, Design Tools, and Opportunities," IEEE Industrial Electronics Magazine, vol. 7, no. 2, pp. 17-26, 2013.

[3] B. Ji, X. Song, E. Sciberras, W. Cao, Y. Hu, and V. Pickert, "Multiobjective Design Optimization of IGBT Power Modules Considering Power Cycling and Thermal Cycling," IEEE Transactions on Power Electronics, vol. 30, no. 5, pp. 2493-2504, 2015.

[4] K. Ma, M. Liserre, F. Blaabjerg, and T. Kerekes, "Thermal Loading and Lifetime Estimation for Power Device Considering Mission Profiles in Wind Power Converter," IEEE Transactions on Power Electronics, vol. 30, no. 2, pp. 590-602, 2015.

[5] P. Hagler, P. Henson, and R. W. Johnson, "Packaging Technology for Electronic Applications in Harsh High-Temperature Environments," IEEE Transactions on Industrial Electronics, vol. 58, no. 7, pp. 2673-2682, 2011.

[6] Y. Chan-Su, P. Regli, J. Waldmeyer, and W. Fichtner, "Static and dynamic thermal characteristics of IGBT power modules," in 11th International Symposium on Power Semiconductor Devices and ICs. ISPSD'99 Proceedings (Cat. No.99CH36312), 1999, pp. 37-40.
[9]

[15] Y. Yu, T. T. Lee, and V. A. Chiriac, "Compact Thermal ResistorCapacitor-Network Approach to Predicting Transient Junction Temperatures of a Power Amplifier Module," IEEE Transactions on Components, Packaging and Manufacturing Technology, vol. 2, no. 7, pp. 1172-1181, 2012.

[16] M. Rencz and V. Szekely, "Dynamic thermal multiport modeling of IC packages," IEEE Transactions on Components and Packaging Technologies, vol. 24, no. 4, pp. 596-604, 2001.

[17] Z. Wang and W. Qiao, "A Physics-Based Improved Cauer-Type Thermal Equivalent Circuit for IGBT Modules," IEEE Transactions on Power Electronics, vol. 31, no. 10, pp. 6781-6786, 2016.

[18] T. Kojima, Y. Yamada, Y. Nishibe, and K. Torii, "Novel RC Compact Thermal Model of HV Inverter Module for ElectroThermal Coupling Simulation," in 2007 Power Conversion Conference - Nagoya, 2007, pp. 1025-1029.

[19] U. Drofenik, D. Cottet, A. Musing, J. Meyer, and J. W. Kolar, "Computationally Efficient Integration of Complex Thernal MultiChip Power Module Models into Circuit Simulators," in 2007 Power Conversion Conference - Nagoya, 2007, pp. 550-557.

[20] A. Castellazzi, "Comprehensive Compact Models for the Circuit Simulation of Multichip Power Modules," IEEE Transactions on Power Electronics, vol. 25, no. 5, pp. 1251-1264, 2010.

[21] M. Musallam and C. M. Johnson, "Real-Time Compact Thermal Models for Health Management of Power Electronics," IEEE Transactions on Power Electronics, vol. 25, no. 6, pp. 1416-1425, 2010.

[22] C. Batard, N. Ginot, and J. Antonios, "Lumped Dynamic Electrothermal Model of IGBT Module of Inverters," IEEE Transactions on Components, Packaging and Manufacturing Technology, vol. 5, no. 3, pp. 355-364, 2015.

[23] K. Ma, A. S. Bahman, S. Beczkowski, and F. Blaabjerg, "Complete Loss and Thermal Model of Power Semiconductors Including Device Rating Information," IEEE Transactions on Power Electronics, vol. 30, no. 5, pp. 2556-2569, 2015.

[24] J. Ye, K. Yang, H. Ye, and A. Emadi, "A Fast Electro-Thermal Model of Traction Inverters for Electrified Vehicles," IEEE Transactions on Power Electronics, vol. 32, no. 5, pp. 3920-3934, 2017.

[25] K. Yang, "TRANSIENT ELECTRO-THERMAL ANALYSIS OF TRACTION INVERTERS," M.A.Sc, Department of Mechanical Engineering, McMaster University 2015.

[26] T. Gradinger and G. Riedel, "Thermal Networks for Time-Variant Cooling Systems: Modeling Approach and Accuracy Requirements for Lifetime Prediction," in 2012 7th International Conference on Integrated Power Electronics Systems (CIPS), 2012, pp. 1-6.

[27] X. Du, J. Zhang, S. Zheng, and H. Tai, "Thermal Network Parameter Estimation Using Cooling Curve of IGBT Module," IEEE Transactions on Power Electronics, vol. 34, no. 8, pp. 7957-7971, 2019. 


\section{IEEE POWER ELECTRONICS REGULAR PAPER/LETTER/CORRESPONDENCE}

[28] P. L. Evans, A. Castellazzi, and C. M. Johnson, "Automated Fast Extraction of Compact Thermal Models for Power Electronic Modules," IEEE Transactions on Power Electronics, vol. 28, no. 10, pp. 4791-4802, 2013.

[29] J. Reichl, J. M. Ortiz-Rodríguez, A. Hefner, and J. Lai, "3-D Thermal Component Model for Electrothermal Analysis of Multichip Power Modules With Experimental Validation," IEEE Transactions on Power Electronics, vol. 30, no. 6, pp. 3300-3308, 2015.

[30] H. Li et al., "Thermal Coupling Analysis in a Multichip Paralleled IGBT Module for a DFIG Wind Turbine Power Converter," IEEE Transactions on Energy Conversion, vol. 32, no. 1, pp. 80-90, 2017.

[31] S. Bouguezzi, M. Ayadi, and M. Ghariani, "Developing a Simplified Analytical Thermal Model of Multi-chip Power Module," Microelectronics Reliability, vol. 66, pp. 64-77, 2016/11/01/2016.

[32] Z. Wang, W. Qiao, B. Tian, and L. Qu, "An effective heat propagation path-based online adaptive thermal model for IGBT modules," in 2014 IEEE Applied Power Electronics Conference and Exposition - APEC 2014, 2014, pp. 513-518.

[33] T. K. Gachovska, B. Tian, J. L. Hudgins, W. Qiao, and J. F. Donlon, "A real-time thermal model for monitoring of power semiconductor devices," IEEE Transactions on Industry Applications, vol. 51, no. 4, pp. 3361-3367, 2015.

[34] Z. Wang, B. Tian, W. Qiao, and L. Qu, "Real-Time Aging Monitoring for IGBT Modules Using Case Temperature," IEEE Transactions on Industrial Electronics, vol. 63, no. 2, pp. 11681178, 2016.

[35] A. S. Bahman, K. Ma, P. Ghimire, F. Iannuzzo, and F. Blaabjerg, "A 3-D-Lumped Thermal Network Model for Long-Term Load Profiles Analysis in High-Power IGBT Modules," IEEE Journal of Emerging and Selected Topics in Power Electronics, vol. 4, no. 3, pp. 1050-1063, 2016.

[36] C. Qian et al., "Thermal Management on IGBT Power Electronic Devices and Modules," IEEE Access, vol. 6, pp. 12868-12884, 2018.

[37] Mathworks. [Online]. Available: https://uk.mathworks.com/matlabcentral/fileexchange/48026evolutionary-curve-fitting.(Accessed:26-May-2017).

[38] A. S. Bahman, K. Ma, and F. Blaabjerg, "A Lumped Thermal Model Including Thermal Coupling and Thermal Boundary Conditions for High-Power IGBT Modules," IEEE Transactions on Power Electronics, vol. 33, no. 3, pp. 2518-2530, 2018.

[39] M. Shahjalal, H. Lu, and C. Bailey, "Electro-thermal modelling of multichip power modules for high power converter application," in 2017 18th International Conference on Electronic Packaging Technology (ICEPT), 2017, pp. 940-945.

[40] M. Ahmed, "Design, Construction and Evaluation of a Power-Dense $12 \mathrm{~V}$ to $48 \mathrm{~V}$ Bidirectional DC-DC converter for Automotive Applications," 2013.

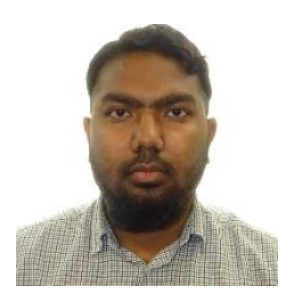

Mohammad Shahjalal received the B.Sc. degree in electrical and electronics engineering from Chittagong University of Engineering and Technology, Bangladesh, in 2009, the M.Sc. degree in Digital image and signal processing from the University of Manchester, Manchester, United Kingdom, in 2013, and the Ph.D. degree in computing and mathematical sciences from the University of Greenwich, Greenwich, U.K., in 2018. He worked as a lecturer with the Department of Electrical and Electronics Engineering, International Islamic University of Chittagong, Bangladesh, in 2010-2012. Since 2018 he has been leading the project titled thermal (entropic heat) characterisation of li-ion pouch cells used in Jaguar's first full-fledged electric car I_PACE in WMG. His current research interests include electrothermal modelling, packaging, and reliability of power electronic systems and components and entropic heat modelling of energy storage systems in electric vehicle.

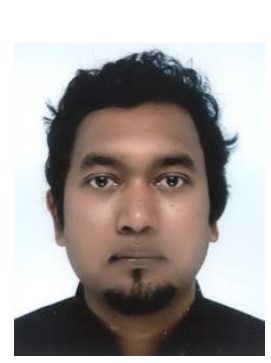

Rishad Ahmed (M'14-) received the B.Sc. degree from the Bangladesh University of Engineering and Technology (BUET), Dhaka, Bangladesh in 2011, and the M.Sc. degree (with Distinction) and the Ph.D. degree from the University of Manchester, Manchester, U.K., in 2013 and 2017, respectively. Since Sept. 2017, he has been working as a design engineer for automotive power electronics at Dynex Semiconductor, U.K. In Feb. 2020, he has taken up an academic role as an Assistant Professor at the University of Nottingham, U.K.

His research interests include wideband-gap devices and high-frequency converters.

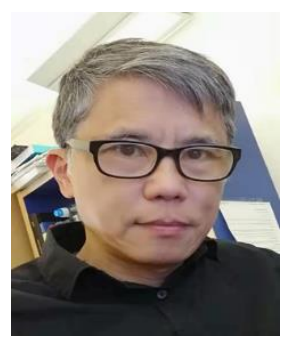

Hua Lu Hua Lu (M’01-SM'08) was born in received the MSc degree in Condensed Matter Physics from Wuhan University, China, in 1988, and the PhD degree in Computational Physics from the University of Edinburgh, Scotland, UK in 1992. $\mathrm{He}$ is now a Reader in Computational Science at the University of Greenwich, London, UK. His recent research interests are in the analysis of the design optimization and reliability of electronics systems using computational methods.

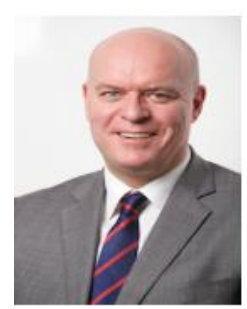

Chris Bailey HRIS BAILEY (A'01, M'03, SM'05) is Professor of Computational Mechanics and Reliability at the University of Greenwich, London, United Kingdom. I received my $\mathrm{PhD}$ in Computational Modelling from Thames Polytechnic in 1988, and an MBA in Technology Management from the Open University in 1996. Before joining Greenwich in 1991, I worked for three years at Carnegie Mellon University (USA) as a research fellow in materials engineering.

My research has resulted in over 250 publications. I am currently an Associate Editor for the CPMT Transactions and have been a guest editor on the journal of Soldering and Surface Mount Technology. I am also a committee member of the Innovative Electronics Manufacturing Research Centre (IeMRC) in the UK and have participated in a number of UK Government sponsored overseas missions to promote collaboration and review electronic packaging technologies. Recently I became a member of the working group writing a new IEEE standard for Prognostics and Health Management for Electronic Systems.

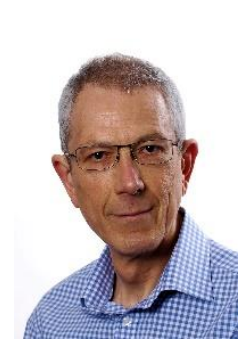

Andrew J. Forsyth (M'98) received the B.Sc.(Eng) degree in Electrical Engineering from Imperial College, London, U.K., in 1981 and the Ph.D. degree in Power Electronics from the University of Cambridge, Cambridge, U.K., in 1987. He was a Design Engineer with GEC Electrical Projects Ltd from 1981 to 1983, a Lecturer at the University of Bath from 1986-1990, and a Lecturer / Senior Lecturer at Birmingham University from 1991 to 2004. Since 2004 he has been Professor of Power Electronics at the University of Manchester,

Manchester U.K. His research interests include highfrequency converters and

magnetic components, converter modelling and control, aerospace and electric vehicle applications. 